\title{
Acid maltase deficiency: a case study and review of the pathophysiological changes and proposed therapeutic measures
}

\author{
HYAM ISAACS, ${ }^{*}$ NERINA SAVAGE, $\dagger$ MARGARET BADENHORST, \\ TONI WHISTLER
}

From the Departments of Physiology, ${ }^{*}$ and Medical Biochemistry, $\dagger$ and the Clinical Neuromuscular Research Laboratory, Department of Physiology, $\ddagger$ Witwatersrand University Medical School, South Africa

SUMMARY An adult patient with lysosomal acid alpha-glucosidase deficiency was fully investigated, and then placed on various forms of therapy with favourable response to a high protein, low carbohydrate diet. The rationale for the employment of this therapy, the problem of acid maltase deficiency and the relationship to weakness and glycogenosome formation with accumulation or otherwise of glycogen within the muscle fibres is discussed.

Deficiency of lysosomal acid alpha-glucosidase (acid maltase) is in most cases associated with abnormal accumulation of glycogen in skeletal muscle. The excessive concentration of glycogen viewed ultramicroscopically is obvious in the sarcoplasm as freelying glycogen and as membrane-bound glycogen sacs known as glycogenosomes. These are seen to be distended lysosomes, some of which have ruptured their glycogen content into the sarcoplasm. On light microscopy the muscle appearance is that of a vacuolar myopathy which on histochemical study shows the presence of excessive acid phosphatase. ${ }^{1}$ In 1932 Putschar $^{2}$ and Pompe ${ }^{3}$ were the first to describe this disorder of glycogen metabolism in infants. Subsequently a late onset or adult form was described by Engel and Dale. ${ }^{4} \mathrm{Hers}^{5}$ ascribed the glycogen storage to acid alpha-glucosidase deficiency. Acid maltase deficiency is classified as glycogenolysis Type $\mathrm{II}^{6}$ and is one of the six major causes of glycogen storage disease.

It has become established over the years that this recessively inherited abnormality of lysosomal acid alphaglucosidase may present clinically in two forms. This subdivision is based on the age of onset, differences in severity, the course of the illness and the fact that these presentations seldom overlap in the affected members of a particular family. The severe

Address for reprint request: Dr H Isaacs, NMRU, Department of Physiology, University of the Witwatersrand Medical School, York Road, Parktown, 2193 South Africa.

Received 6 June 1985 and in revised form 7 October 1985. Accepted 20 October 1985 form of the disease occurs in infancy and presents with severe cardiomegaly, hepatomegaly, neurological involvement and the baby seldom lives for more than 2 years. The more benign form occurs in juveniles and in adults and is compatible with a reasonable lifespan.

The observations of an affected adult patient who has been studied and treated on a high protein, carbohydrate restricted diet over a 6 year period, are presented.

\section{Patient's history \& examination}

The patient, a caucasian female (fig 1) was first seen at the age of 29 years. She is the only child of healthy parents and there was no history of neuromuscular disease in the family. She complained of.weakness of her thigh muscles and stated that this symptom had been slowly progressive over the past 16 years. At the age of 26 years her left quadriceps was biopsied and a diagnosis of limb-girdle dystrophy was made.

Clinical examination revealed that the skeletal muscles were generally weaker than normal, the proximal more involved than the distal and the quadriceps muscles of the thighs most severely affected. Her weakness was such that she was unable to get up from the consulting room chair without the aid of her arms, was unable to climb a single 6" $(15 \mathrm{~cm})$ step without utilising the banister and could not elevate her legs against gravity when lying in the supine position. Respiration was laboured and accessory respiratory muscle use was obvious. The tendon reflexes, with the exception of the knee jerks, were present and equal. In particular, the eye muscles were normal, the tongue was of normal size and the rest of the cranial nerves normal. Sensation and coordination were normal. No other abnormalities were noted. 


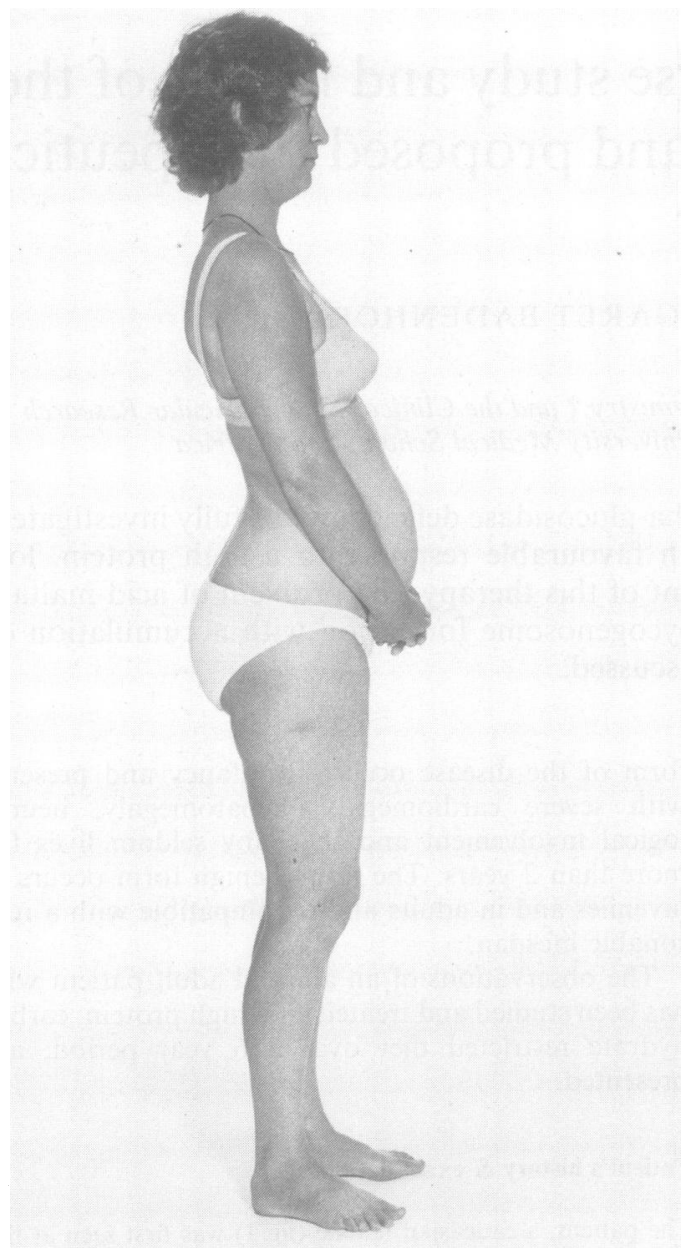

Fig 1 Side-view of the patient taken at the age of 33 years in the early stages of her pregnancy. Her lordotic stance is noted.

\section{Investigations}

Routine blood tests which included liver, thyroid and renal function studies were normal. The serum creatine kinase was elevated to $1455 \mathrm{IU} / 1$ (normal 0-170 IU/1), serum aldolase $17.5 \mathrm{IU} / 1$ (normal 0.5-3.1 IU/1). The ECG showed inversion of the T waves in Std. III and AVF and right axis deviation. Vital capacity in the standing position was 2.4 litres, FEV $70 \%$ of predicted normal. Chest radiographs were normal.

\section{Muscle studies}

Biochemistry Alpha 1-4 glucosidase activity determined radioactivity ${ }^{5}$ was $52.6 \mathrm{dpm} / \mathrm{min} / \mathrm{g}$ (control values of 309.3 \pm 54.9 ) measured by the incorporation of $\mathrm{Cl} 4$ maltase into glycogen. The glycogen content was $90.4 \mathrm{~g} / \mathrm{mg}$ protein (normal control $12.8 \mathrm{~g} / \mathrm{mg}$ protein). Iodine spectral analysis of the glycogen was normal. Myophosphorylase activity was normal. The glucose tolerance test in response to a $50 \mathrm{~g}$ load was abnormal at 30 minutes, reaching a level of $260 \mathrm{mg} / \mathrm{dl}$. The plasma insulin and growth hormone responses were normal. The blood glucose response to epinephrine and glucagon was normal. Amino acid response to a protein load (lean beef) of $4 \mathrm{~g} / \mathrm{kg}$ body weight after a 24-hour period of fasting produced a considerable increase in branded chain amino acid activity (BCAA) peaking at 3 hours (fig 2). These results for BCAA are similar to those described by Slonim et al in 1983 .?

Electromyography The abnormal findings were most severe in the proximal muscles of the lower limbs. The motor-unit potentials were of short duration, mostly polyphasic and of low voltage. Occasional myotonic-like bursts of activity were recorded. In the less severely involved mus-

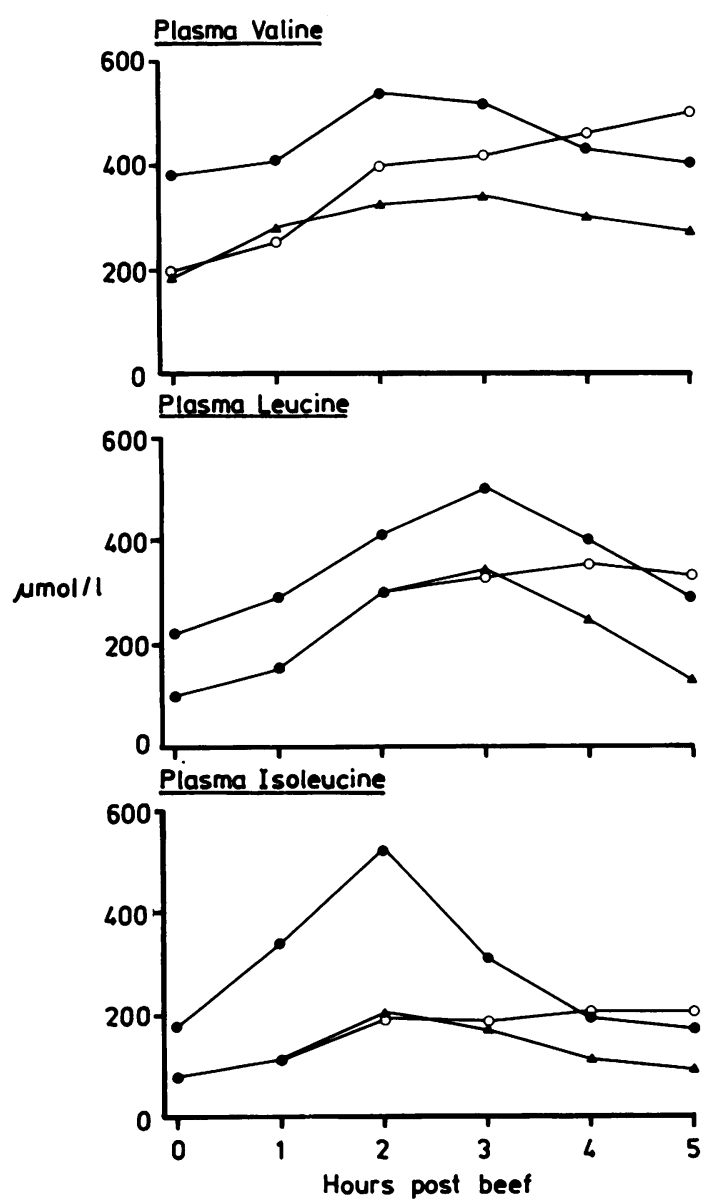

Fig 2 The plasma valine, leucine and isoleucine levels after lean beef consumption ( $4 \mathrm{gm} / \mathrm{kg}$ body weight)

$\bigcirc-\mathrm{O}-$ control subjects

$\Delta-\mathbf{\Delta}$-before protein diet treatment

-3 years after protein diet treatment 
cles there were occasional high-voltage polyphasic units mixed with low voltage activity.

Nerve conduction studies of both motor and sensory modalities in both upper and lower limbs were normal as was the myoneural junctional response to repetitive stimulation varying between 2 and $20 \mathrm{H}_{2}$.

Histology \& histochemistry The left quadriceps muscle was biopsied under local anaesthesia. The histology revealed gross distortion of the muscle fibres (fig 3). Most of the fibres were vacuolated, some entirely disrupted and fibrous and fatty infiltration was prominent. The vacuole contents stained blue with haematoxylin and eosin (H \& E) and red with a modified trichrome stain. The PAS stain revealed the presence of excessive glycogen which appeared to be totally removed by diastase (spit) digestion. Widespread presence of acid phosphatase was noted. There was no evidence of metachromatic or of acid mucopolysaccharide material present.

Histochemical staining for phosphorylase, NAD diaphorase, succinic dehydrogenase and ATPases at $\mathrm{pH} 9 \cdot \mathbf{4}$, 4.3 and 4.6 confirmed that both fibre types were involved, though the Type 1 fibres were far more severely affected and universally smaller than the Type 2 (fig 4).

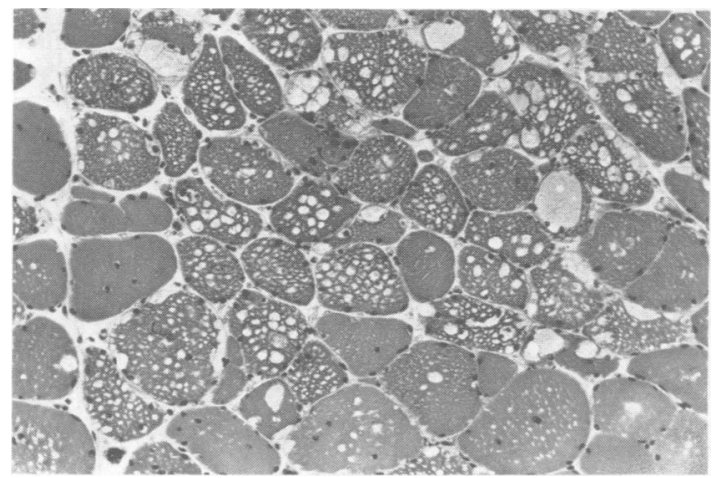

Fig $3 H \&$ preparation demonstrating the marked variability in fibre size, the extreme vacuolation of the fibres and centralisation of many of the nuclei. $(\times 100)$.

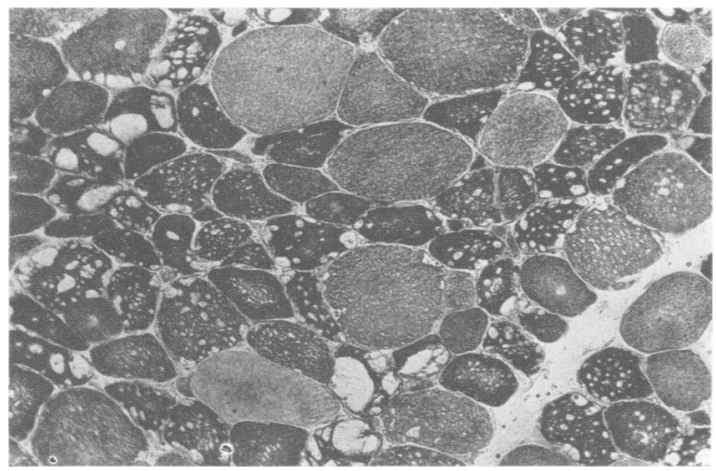

Fig $4 N A D$ preparation demonstrating that the Type 1 fibres are more affected than the Type 2 fibres and are present in greater numbers. $(\times 100)$.
Electron microscopy On electron microscopic examination the massive glycogen accumulation was observed in both the sarcoplasm and in lysosomal vacuoles (fig 5). The swollen lysosomes possessed a single limiting membrane, some intact, others ruptured having discharged their glycogen contents into the sarcoplasm. Glycogen was also seen in occasional distended, intact and also in disrupted mitochondria. Membrane-bound glycogen sacs were also present in the satellite cells. There was marked depletion and distortion of the myofibrils by internal and external glycogen (fig 6). The lysosomal glycogen was frequently seen as being clumped together in a regular pattern (fig 7). Some of the clumped material could be identified under higher magnification as closely packed glycogen granules but many of these bodies had transformed into the electron dense unstructured material (fig 8).

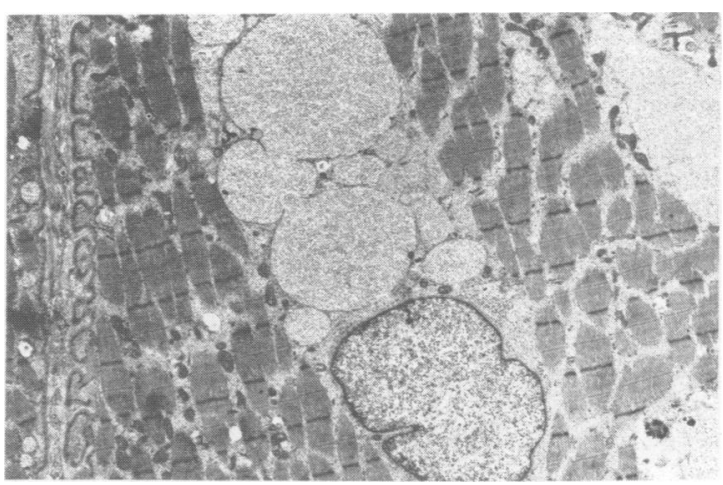

Fig 5 Demonstrating the destruction of the myofibrillar pattern by distended glycogen-containing sacs and free-lying glycogen accumulating between the muscle fibres. Marked folding of the basement membrane is also noted. A centrally-lying nucleus is also seen. $(\times 3000)$.

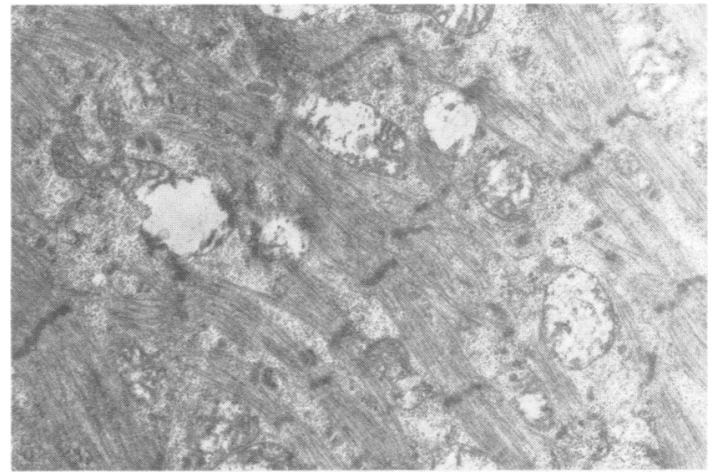

Fig 6 Extreme disruption of the myofibrils, the breakdown of normal mitochrondrial cristae and the accumulation of glycogen within the mitochondria as well as in the sarcoplasm. $(\times 8000)$. 


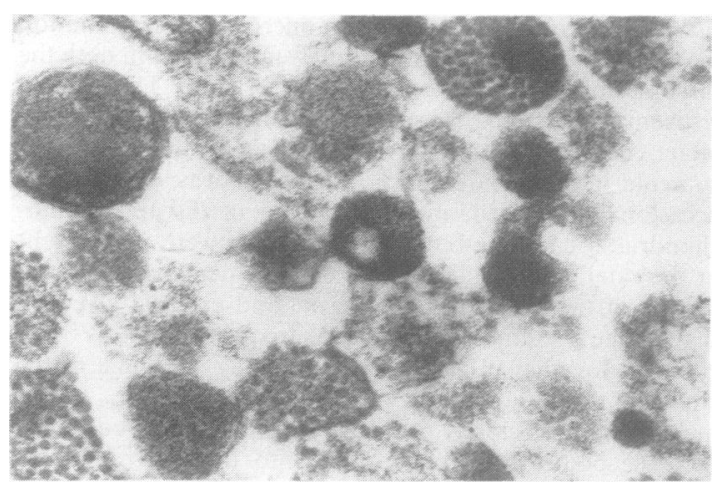

Fig 7 Accumulation of glycogen in regular ball-like patterns. In the middle some show a dense change in structure. $(\times 50000)$.

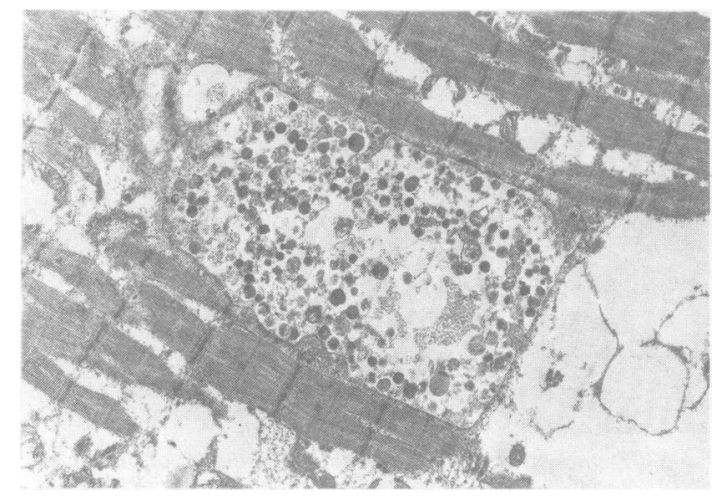

Fig 8 Marked disruption of the myofibrils with broken-down mitochondria and distended sarcoplasmic reticulum together with large areas of vacuolation. In the centre a phagocytic area where the glycogen has formed extremely dense rounded material and can be no longer recognised as glycogen. Scattered amongst these dense areas are lighter ball-like collections of glycogen and much free-lying glycogen. ( $x$ 4000).

Clinical course (table)

The patient was placed on a high protein, low carbohydrate diet consisting of $45 \%$ carbohydrates, $20 \%$ fats and $35 \%$ protein with an approximate calorie value of 1500 . Her improvement over the next 6 months was impressive. She had lost $5 \mathrm{~kg}$ in weight, was able to climb six steps using the banister and could get out of the same office chair without using her arms. Serum CK levels had fallen to $258 \mathrm{IU} / 1$. As we were not sure whether improvement was attributable to the weight reduction, we then decided to let her return to her normal diet for 3 months, though restricted to 1500 calories. The patient deteriorated. We then instituted therapy by prescribing Eltroxin in the hope that thyroid hormone would increase the activity of acid alphaglucosidase and so increase glycogen utilisation. This therapeutic measure was prompted by the knowledge that thyroid insufficiency causes a fall in acid alpha-glucosidase. ${ }^{8}$ Over a period of 3 months she gained $2 \mathrm{~kg}$, became obviously weaker, the creatine kinase increased to $550 \mathrm{IU} / 1$ and the patient requested that the thyroid therapy, which by then had gradually been increased to $0.3 \mathrm{mg}$ daily, be stopped. During the period of thyroid administration, the patient was watched closely for evidence of thyrotoxicosis. This was not reflected clinically and the thyroid function studies at the height of her therapy were still within the upper range of normal. The acid alphaglucosidase measured at this time showed no significant change. The thyroid medication was gradually discontinued and she remained on her normal diet of 1500 calories per day (the carbohydrate content was estimated at $60 \%$, fats $20 \%$ and protein $15-20 \%$ ) for the next three months, over which time she lost $1 \mathrm{~kg}$ in weight. She was weaker, could barely climb three steps and could not get out of the same chair unaided. Her restricted calorie, high protein, low carbohydrate diet was restarted and consequently she lost a further $2 \mathrm{~kg}$ but over the ensuing months her strength gradually improved.

Three years after diagnosis, the muscle biopsy was repeated. At this stage the patient had been on a continuous high protein intake for 1 year. The biochemical and pathological studies produced results which were not significantly different from the initial studies. The CK level was 244 IU/1 and the glucose tolerance test had returned to normal. Protein utilisation showed a rapid rise in BCAA though her basal levels were on the average $120 \mu \mathrm{mol} / 1$ higher (fig 2).

Six years after initial diagnosis she is still stronger and remains on her high protein diet. She is able to climb 20 steps with the aid of her arms pulling on the banister and gets up out of the chair unaided. She can lift her legs against gravity when lying on her back and she can, with some difficulty, get up off the floor unaided, a function which was impossible 6 years earlier. The patient, after many years, became pregnant (fig 1) and has given birth to a healthy daughter. Her vital capacity has improved to 2.6 litres in the standing position and the $\mathrm{FEV}_{1}$ to $75.5 \%$ of predicted normal.

The changes in diet and therapy and the changes in muscle strength and the ability to climb stairs with the aid of a banister

\begin{tabular}{rlllc}
\hline Time & Weight $(\mathrm{kg})$ & Therapy & Calories & No of stairs \\
\hline 0 mths & 67 & High protein low carbohydrate & 1500 & Nil \\
6 mths & 62 & Normal diet & 1500 & 6 \\
9 mths & 63 & + Elthyroxin 0.1-0.3 mg & 1500 & 5 \\
12 mths & 63 & Stopped thyroid medication Normal diet & 1500 & 4 \\
15 mths & 62 & High-protein diet & 1500 & 3 \\
27 mths & 65 & High-protein diet & 1500 & 10 \\
6 years & 66 & High-protein diet & & $20+$ \\
\hline
\end{tabular}




\section{Discussion}

Acid alpha-glucosidase deficiency originally described in children by Pompe ${ }^{3}$ is not confined to the human species. The deficiency occurs in the Lapland dog, ${ }^{9}$ the cat, ${ }^{10}$ in cattle ${ }^{11}$ and in sheep. ${ }^{12}$ These reports have indicated that the deficiency is widespread in the animal world.

A diagnosis of glycogen storage disease Type IIb was established in our patient. The clinical course of acid maltase deficiency in general has been well described. ${ }^{1}$ The virtual non-occurrence of more than one distinctive type occurring in a family, apart from those described by Bush et $a l^{13}$ and the characteristics of the molecular defects ${ }^{14}{ }^{14 b}$ of this disorder vindicates the separation of Type II glycogenolysis into the severe non-surviving infantile (Type IIa) and the relatively benign adult variety (Type IIb). This concept is strongly held by Mehler and Dimauro ${ }^{15}$ who believe that the sub-groups are inherited as distinct autosomal recessive abnormalities. An intermediate or juvenile form characterised by improved survival, though organomegaly due to glycogen accumulation is not infrequent. tends to merge with the adult variety.

A challenging contradiction adding complexity to this disorder is the reports of lysosomal glycogen storage disease in patients with normal acid maltase levels ${ }^{1617}$ The particularly severe involvement of certain muscles is unexplained as is the excessive involvement of Type 1 fibres in AMD (fig 2) and many explanations have been offered to account for the varying severity and the pathogenesis.

The deficiency of acid alpha-glucosidase remains the main reason for glycogen accumulation in this disorder. ${ }^{6}$

Mehler and Dimauro ${ }^{15}$ obtained small amounts of acid maltase from muscle in their long surviving patients but none in the infantile form and the authors state that "the residual acid maltase activity found in the muscles of Type IIb deficiency may not be high enough to be functionally significant." Low levels of acid alpha-glucosidase have been found in other disease states such as myxoedema, in two cases of myotonia congenita, in patients suffering from hypokalaemic periodic paralysis as well as in healthy heterozygotes, none of whom has shown evidence of abnormal glycogen storage. ${ }^{8}$ The induction of hypothyroidism in rats ${ }^{18}$ failed to evoke glycogen storage despite the depletion of acid alpha-glucosidase. Glycogen storage however could be induced in rat liver. heart and skeletal muscle ${ }^{19}$ by the use of an alphaglucosidase inhibitor. Acarbose. The inhibitor, a pseudotetrasaccharide, was administered intraperitoneally. The accumulation of glycogen could be reversed by withdrawing the inhibitor. ${ }^{19}$ The failure to produce glycogen accumulation by inducing acid alpha-glucosidase deficiency in induced hypothyroidism, suggests that thyroid hormone may be necessary for the process of glycogen accumulation. This interpretation could explain the clinical deterioration witnessed in our patient when placed on thyroid supplementation in an attempt to increase the acid alpha-glucosidase level.

Smith et al $^{20}$ and others ${ }^{11521}$ suggested a compensatory mechanism to account for the slow progression of weakness and correlated this with the level of neutral acid maltase which is markedly decreased in skeletal muscle in the infantile form but normal in the adult. This theory, though playing a role, does not explain the cases with normal acid alpha-glucosidase. Neutral maltase as opposed to acid alpha glucosidase is not located in the lysosomes but is bound to the sarcoplasmic reticulum. ${ }^{20}$

Other hypotheses of importance suggest that a leak of acid hydrolysates from lysosomes into the cytocel damages myofibrils and in doing so the acid glucosidase escaping into the sarcoplasm became inactive as the $\mathrm{pH}$ alters, ${ }^{22}$ that lysosomal rupture and glucase accumulation causes enlargement, rupture and eventual destruction of the fibrils, ${ }^{23}$ that phosphorylase deficiency aggravates the disorder. ${ }^{24}$ This deficiency however was not found by other authors. ${ }^{25-27}$ Furthermore it is established that the amount of glycogen accumulation in muscle differs from patient to patient and may even be normal. ${ }^{121}$ Variation in glycogen concentration does not correlate with the loss of power or elucidate the reason for glycogenosome formation or autophagy which are prominent features of this disorder.

The formation of glycogenosomes, a prominent feature of this disorder warrants comment. Glycogenosomes are not confined to acid maltase deficiency but also occur in the glycogen storage Type III and IV variants, in phosphorylase B kinase deficiency and rarely in normal muscle (fig 9). ${ }^{28}$ In these other forms

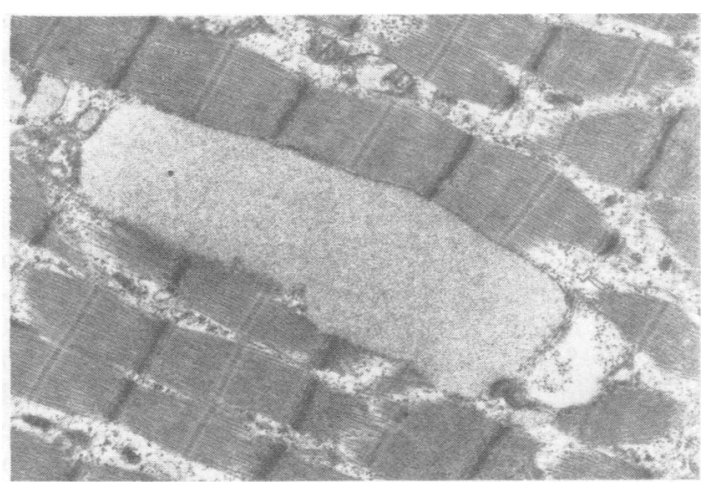

Fig 9 A glycogenosome seen in normal muscle. $\times 6000$ ). 
of glycogen storage disease, the level of acid alphaglucosidase is normal and this confirms the belief that the formation of glycogenosomes need not depend on acid alpha-glucosidase deficiency. ${ }^{29}$

That the glycogen in acid maltase deficiency may have undergone some change or be present in a form which is not available for glycolysis has been postulated $^{30}$ and an abnormality of the short outer branches of the glycogen has been found..$^{30}$ Though the extracted glycogen appears to be chemically normal, the electron dense change seen in many of the closely packed glycogen balls, suggests a physical change (figs 7,8 ). The way the lysosomes handle this change is of the utmost importance.

The lysosomal enzymes play a major role in this disorder; for example cleavage of the outer branches of glycogen up to the alpa 1-6 linkage is a function of neutral maltase. Lysosomal enzymes ${ }^{31} 32$ must be covalently labelled with a sugar phosphate for incorporation of the enzyme into the lysosome. Failure in labelling results in the acid alpha-glucosidase remaining in the neutral $\mathrm{pH}$ media of the sarcoplasm where, as previously stated, it becomes inactive. The localisation of acid alpha-glucosidase compartmentally has as yet not been adequately achieved. ${ }^{17}$ Permeability and incorporation of glycogen into the lysosome does not seem to be at fault and this aspect has been fully studied. ${ }^{33}$ The mechanism whereby the lysosomes ingest such vast quantities of glycogen and are able to do so in occasional cases even in the presence of normal levels of acid alpha-glucosidase, remains obscure. It has been shown that most of the normal glycogen is not digested in the lysosome but that the extremely large molecular-sized glycogen bodies are. ${ }^{34} 35$ In the light of our present knowledge it appears that a deficiency of alpha-glucosidase does not initiate autophagy but the large glycogen molecule itself seems able to stimulate this process. ${ }^{36}$ The reason why large glycogen macromolecules are formed is unknown and whether glycogen autophagy and degradation depend upon the same or different systems is still to be established. Failure of utilisation of glycogen is not the cause of the muscle weakness in acid maltase deficiency and the process of gluconeogenesis is intact.

\section{Therapy}

Prevention of the disease by in utero detection of an involved foetus has become an important contribution in the control of this disorder. Detection of AMD Type IIa in a known carrier may be achieved by culturing cells extracted from the amniotic fluid and demonstrating glycogen accumulation. ${ }^{37}$ More recently a rapid diagnostic method has been described; ${ }^{38}$ amniocentesis is carried out at $15-18$ weeks and the affected amniotic fluid cells are found to show glycogen accumulation on electron microscopic study. Identifying the involved foetus in this manner offers the parents the option of abortion.

As is the case in many neuromuscular disorders, the sufferers often neglect to make full use of their remaining muscle, for example pulmonary function may be improved by means of diaphragm training by using forced expiratory exercises. ${ }^{39}$

Since the recognition of acid maltase deficiency, various therapies have been tried. Restriction of carbohydrate in the diet was attempted without avail. ${ }^{1}$ Attempts at mobilisation of glycogen by the administration of ephedrine and glucagon were equally unsuccessful. ${ }^{1}$ Fructose feeding was of no real value. ${ }^{26}$ Attempts at stimulating acid alphaglucosidase by the administration of thyroid hormone in our patient caused deterioration. Treatment with prednisone in conjunction with a low carbohydrate diet was of no value. ${ }^{40}$ Vitamin $A$, progesterone and hyperbaric oxygen used as lysosome unstabilising agents, ketogenic diets and oral acid alphaglucosidase derived from fungi have been valueless. ${ }^{41}$ Administration of oral acid maltase prepared from bacteria ${ }^{42}$ as well as acid alpha-glucosidase prepared from human placenta ${ }^{43}$ proved to be of no value. Administration of lysosome labelling agents combined with acid alpha-glucosidase prepared from bacteria was unsuccessful. ${ }^{44}$ The administration of acid alpha-glucosidase entrapped in liposomes has been used $^{45}$ but again the liposomes failed to reach the muscle tissue. Gregoriadis ${ }^{46}$ suggested that the liposomes could be directed to muscle tissue by attaching specific antigens to the liposomal surface. This process and the use of enzyme polymers has as yet not met with success. ${ }^{47}$

Slonim $\mathrm{et} \mathrm{al}^{7}$ suggested that the disturbance in glycogen metabolism caused protein utilisation to occur as an alternate energy source which ultimately leads to a state of relative protein deficiency and muscle weakness. They demonstrated the early rise and fall of BCAA as occurred in our case. That this is not indicative of increased degradation is shown by calculations ${ }^{7}$ which demonstrated a concurrent fall in Cethepsin $\mathrm{D}$ and $\mathrm{H}$ and proteinase activity suggesting an increase in tissue utilisation of BCAA which are the principal amino-acids for muscle protein synthesis.

This glycogenogenic switch seems to have merit and our patient's progress substantiates this. Towards the end of three years of treatment, our patient's resting level of BCAA had increased by more than $120 \mu \mathrm{mol} / 1$ (fig 2).

The improvement in strength at the 3 year period was not associated with improvement histologically or with higher acid alpha-glucosidase activity but the 
CK and aldolase fell significantly and remain at a level just above normal. It is suggested that this regimen be tried more extensively.

We gratefully acknowledge the financial support of the Medical Research Council of South Africa, the University of the Witwatersrand and the Muscular Dystrophy Research Foundation of South Africa for this study.

\section{References}

${ }^{1}$ Engel AG, Gomez MR, Seybold ME, Lambert EH. The spectrum and diagnosis of acid maltase deficiency. Neurology (Minneap) 1973;23:95-106.

${ }^{2}$ Putschar W. Uber angeborene Glykogenspeicherkrankheit des Herzens. Beitr Pathol Anat Allg Pathol 1932;90:222-31.

${ }^{3}$ Pompe JC. Over idiopathische hypertrophie van het hart. Ned Tijdsch Geneeskd 1932;76:304-11.

${ }^{4}$ Engel AG, Dale AJD. Autophagic glycogenosis of late onset with mitochondrial abnormalities: light and electron microscopic observations. Mayo Clin Proc 1968;43:233-79.

${ }^{5}$ Hers HG. $\propto$ Glucosidase deficiency in generalized glycogen storage disease (Pompe's disease). Biochem $J$ 1963;86:11-6.

${ }^{6}$ Cori GT. Biochemical Aspect of Glycogen Deposition Disease. Mod Probl Paediatr 1957;3:344-58.

${ }^{7}$ Slonim RA, Coleman MA, McElligot JN, Hirschorn GU, Ladabie RM, Mrak R, Evans OB, Shipp E, Presson R. Improvement of muscle function in acid maltase deficiency by high protein diet. Neurology (Cleveland) 1983;33:34-8.

${ }^{8}$ Engel AG, Gomez MR. Acid maltase levels in muscle in heterozygous acid maltase deficiency and in non-weak and neuromuscular disease controls. J Neurol Neurosurg Psychiatry 1970;33:801-7.

${ }^{9}$ Mostafa IE. A case of glycogenic cardiomegaly in a dog. Acta Vet Scand 1970;11:197-9.

${ }^{10}$ Sandstrom B, Westman J, Ockerman PA. Glycogenosis of the central nervous system in the cat. Acta Neuropathol (Berl) 1969;14:194-6.

${ }^{11}$ Richards RB, Edwards JR, Cook RD, White RR. Bovine generalised glycogenosis. J Neuropathol Appl Neurobiol 1977; 12:147-52.

${ }^{12}$ Manktelow BW, Hartley WJ. Generalised glycogen storage disease in sheep. J Comp Pathol 1975;85:139-42.

${ }^{13}$ Busch HFM, Koster JF, van Weerden TW. Infantile and adult-onset acid maltase deficiency occurring in the same family. Neurology (Minneap) 1979;29:415-6.

${ }^{14}$ Beratis NG, La Bodie GU, Hirschorn K. Characterization of the molecular defect in infantile and adult $\alpha$ glucosidase deficiency fibroblasts. $J$ Clin Invest 1978:62:1264-74.

${ }^{14 \mathrm{~b}}$ Beratis NG, La Bodie GU, Hirschorn K. Genetic Heterogenicity in Acid $\alpha$ Glucosidase Deficiency. Am J Hum Genet 1983;35:21-33.

${ }^{15}$ Mehler M, Dimauro S. Residual acid maltase activity in late-onset acid maltase deficiency. Neurology (Min- neap) 1977;27:178-84.

${ }^{16}$ Danon MJ, Shin JDL, Di Mauro S, Manaligod JR, Eastwood A, Sakkubai N, Schliselfeld LH. Lysosomal glycogen storage disease with normal acid maltase. Neurology (NY) 1981;31:51-7.

${ }^{17}$ Riggs JE, Schochet SS, Gutmann L Jr, Shanske S, Neal WA, Di Mauro S. Lysosomal glycogen storage disease without acid maltase deficiency. Neurol (Cleveland) 1983;33:873-7.

${ }^{18}$ McCormick D, Allen IV, Hurwitz LJ. Acid-maltase deficiency and hypothyroidism. Lancet 1971;1:85-7.

${ }^{19}$ Lullman-Rauch R. Lysosomal Glycogen Storage Mimicking the Cytological Picture of Pompe's Disease as Induced in Rats by Injection of an $\alpha$-Glucosidase Inhibitor. Virchows Arch (Cell Pathol) 1981;38:89-100.

${ }^{20}$ Smith EE, Taylor PM, Whelan WJ. Enzymatic processes in glycogen metabolism. In: Dickens F, Randle PJ, Whelan W, eds. Carbohydrate Metabolism and its Disorders. New York: Academic Press 1968:89-138.

${ }^{21}$ Angelini C, Engel AG. Comparative study of acid maltase deficiency: Biochemical differences between infantile, childhood and adult types. Arch Neurol 1972;26:344-9.

${ }^{22}$ Hers HG, Van Hoof F. Glycogen-storage diseases: type II and Type VI glycogenosis. In: Dickens F, Randle PJ, Whelan W, eds. Carbohydrate Metabolism and its Disorders. London, New York: Academic Press 1968;2:151-60.

${ }^{23}$ Griffin JL. Infantile acid maltase deficiency: Muscle fibre hypertrophy and the ultrastructure of end-stage fibres. Virchows Arch (Cell Pathol) 1984;45:37-50.

${ }^{24}$ Hug C, Schubert WK, Chuck G. Loss of cyclic 3'5'-AMP dependent kinase and reduction of phosphorylase kinase in skeletal muscle of a girl with deactivated phosphorylase and glycogenosis of liver and muscle. Biochem Biophys Res Commun 1970;40:982-8.

${ }^{25}$ Hudgson P, Gardner-Medwin D, Wortsford M, Pennington RJT, Walton JN. Adult myopathy from glycogen storage disease due to acid maltase deficiency. Brain 1968;91:435-60.

${ }^{26}$ Engel AG. Acid maltase deficiency in adults: studies in four cases of a syndrome which may mimic muscular dystrophy or other myopathies. Brain 1970;93:599-616.

${ }^{27}$ Di Mauro S, Stern LZ, Mehler M, Nagel RE, Payne G. Adult onset acid maltase deficiency. A post-mortem study. Muscle \& Nerve 1978;1:27-36.

${ }^{28}$ Iwamasa T, Ninomiya N, Fukuda S, Hamada T, Hirashma M, Osame M. Studies related to the mechanism of glycogenosome formation. Pathol Res Pract 1983;176:236-52.

${ }^{29}$ Marquez A, Finol HJ. Glycogenosomes in fibres of human normal skeletal muscles. An electron microscopic study. Inst Med Exp Univ Cent Venezuela Sabana Grande Caracas Venezuela. Acta Neuropathol 1984;63:347-50.

${ }^{30}$ Smith HL, Amick LD, Sidbury JB. Type II glycogenosis: Report of a case with four-year survival and absence of acid maltase associated with an abnormal glycogen. $\mathrm{Am}$ $J$ Dis Child 1966;111:475-81.

${ }^{31}$ Sando GN, Neufeld EF. Recognition and receptormediated uptake of lysosomal enzyme L-iduronidase, by cultured human fibroblasts. Cell 1977;12:619-27.

${ }^{32}$ Kaplan A, Achard DT, Shy WS. Phosphohexosyl com- 
ponents of a lysosomal enzyme are recognised by pinocytosis receptors on human fibroblasts. Proc Natl Acad Sci USA 1977;74:2026-30.

${ }^{33}$ Reyngoud DJ, Jager JM. The permeability properties of the lysosomal membrane. Biochim Biophys Acta 1977;472:419-49.

${ }^{34}$ Iwamasa T, Tsuru T, Hamada T, Takeuchi T. Physiochemical properties of glycogen extracted from liver of Type II glycogenosis. Acta Histochem Cytochem 1979;12:197-205.

${ }^{35}$ Geddes R, Stratton GC. The influence of lysosomes on glycogen metabolism. Biochem J 1977a;163:193-200.

${ }^{36}$ Geddes T, Harvey JD, Wills PR. The Molecular size and shape of liver glycogen. Biochem J 1977b;163:201-9.

${ }^{37}$ Nadler HL, Messina AM. In-utero detection of Type II glycogenosomes (Pompe's disease). Lancet 1969;2:1277-8.

${ }^{38}$ Hug G, Saoukup S, Ryan M, Chuck BA. Rapid prenatal diagnosis of glycogen-storage disease Type II by electron microscopy of uncultured amniotic fluid cells. $N$ Engl J Med 1984;310:1018-22.

${ }^{39}$ Martin RJ, Sufit RL, Ringel SP, Hudgel DW, Hill PL. Respiratory improvement by muscle training in adult onset acid maltase deficiency. Muscle Nerve 1983;6:201-3.

${ }^{40}$ Papapetropoulos T, Paschalis C, Manda P. Myopathy due to juvenile acid maltase deficiency affecting exclu- sively the Type I fibres. $J$ Neurol Neurosurg Psychiatry 1984;47:213-5.

${ }^{41}$ Hug G, Schubert WK. Lysosomes in Type II glycogenosis: changes during administration of extract from Aspergillus Niger. J Cell Biol 1967;35:C1-C6.

${ }^{42}$ Baudhuin P, Hers HG, Loeb H. An electron microscopic and biochemical study of Type II glycogenosis. Lab Invest 1964;13:1139-52.

${ }^{43}$ De Barsy $T$, Jacquemin P, Van Hoof F, Hers HG. Enzyme replacement in Pompe's disease: An attempt with purified human acid $\alpha$-glucosidase. Birth Defects 1973;9:184-90.

${ }^{44}$ Hug G, Schubert WK, Soukup S. Treatment related observations in solid tissues, fibroblast cultures and amniotic fluid cells of Type II glycogenosis: Hurler disease and metachromatic leukodystrophy. Birth Defects 1973;9:160-3.

${ }^{45}$ Tyrrell DA, Ryman BEE, Keeton BR, Dubowitz V. Use of liposomes in treating Type II glycogenosis. $\mathrm{Br} \mathrm{Med} \mathrm{J}$ 1976;2:88-89.

${ }^{46}$ Gregoriadis G. The Carrier potential of liposomes in biology and medicine. $N$ Engl J Med 1976;295:704-10.

${ }^{47}$ Poznansky MJ, Bhardway D. $\alpha-1,4$ Glucosidase-albumin polymers: in vitro properties and advantages for enzyme replacement therapy. Can J Physiol Pharmacol 1980;58:322-5. 